\title{
Characterization of protein-antiproteinase imbalance in bronchoalveolar lavage from patients with pneumonia
}

\author{
J. Braun, K. Dalhoff, B. Schaaf, W.G. Wood, K.J. Wießmann
}

\begin{abstract}
Characterization of proteinase-antiproteinase imbalance in bronchoalveolar lavage from patients with pneumonia. J. Braun, K. Dalhoff, B. Schaaf, W.G. Wood, K.J. Wießmann. CERS Journals Ltd 1994.

ABSTRACT: In order to clarify the mode of inactivation of alpha ${ }_{1}$-proteinase inhibitor (alpha $a_{1}$-PI) in pneumonia, 21 immunocompetent patients and 19 immunocompromised patients with acute pneumonia (Groups I and II) were studied. Nine patients successfully treated for pneumonia and $\mathbf{1 0}$ healthy volunteers served as controls (Groups III and IV, respectively).

The concentrations of alpha ${ }_{1}$-PI, elastase and myeloperoxidase (MPO) in bronchoalveolar lavage fluid (BALF) were determined using a luminometric assay. Elastase inhibition capacity was determined using a colorimetric assay. Thus, the functional activity of alpha $a_{1}$-PI was calculated.

Both elastase and MPO were significantly higher in group I, when compared with the other groups. The mean concentration of alpha $a_{1}$-PI was significantly higher in patients with acute pneumonia (Group I $13 \mathrm{mg} \cdot l^{-1}$, Group II $4.22 \mathrm{mg} \cdot l^{-1}$ ) than in Groups III and IV (2.65 and $0.33 \mathrm{mg} \cdot l^{-1}$, respectively), whereas, the proportion of active alpha ${ }_{1}$-PI was significantly lower in Group I than in the other groups. Only a small proportion was present as a complex with elastase (ca. 5.9\%) or in oxidised form (ca. $4.8 \%), 85 \%$ of alpha 1 -PI was irreversibly proteolized. This resulted in free elastase activity in 7 of the 40 patients $(18 \%)$ with acute pneumonia.

We conclude that functional activity of alpha $a_{1}-\mathrm{PI}$ is markedly impaired due to irreversible proteolysis in acute pneumonia, despite high immunological concentrations.

Eur Respir J., 1994, 7, 127-133.
\end{abstract}

Clinic of Internal Medicine, Medical University of Lübeck, Germany.

Correspondence: J. Braun

Klinik für Innere Medizin

Medizinische Universität zu Lübeck

Ratzeburger Allee 160

D-23538 Lübeck 1

Germany

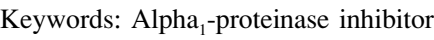
bacterial pneumonia

bronchoalveolar lavage

elastase

neutrophils

oxygen radicals

Received: August 271992

Accepted after revision July 251993
Despite the use of highly active antimicrobial agents, bacterial pneumonia remains the most common cause of death from infectious diseases in industrialized countries [1]. In immunocompetent patients with pneumonia, neutrophils are attracted to the alveolar space by chemotactic stimuli [2], giving rise to the distinct granulocytosis in the bronchoalveolar lavage (BAL). In addition to the desired antimicrobial effect, these neutrophils release potentially toxic products [3] into the alveolar space, that have the ability to produce irreversible damage to the host tissue [4-9]. Neutrophil elastase liberated during this process can be "neutralized" by alpha ${ }_{1}$-proteinase inhibitor $\left(\right.$ alpha $\left._{1}-\mathrm{PI}\right)$, thus protecting lung tissue from proteolysis [4]. Another "two-sided sword" of neutrophils are reactive oxygen species, which are released during active pneumonia $[10,11]$. In the oxidative burst of neutrophils, myeloperoxidase (MPO) plays a major role by catalysing the reaction between hydrogen peroxide and chloride ions, to produce the highly cytotoxic hypochlorous acid $(\mathrm{HOCl})$. Both proteases and reactive oxygen species may lead to inactivation of alpha $a_{1}$-PI, that protects lung tissue from proteolytic damage [4].

In order to define the interaction between toxic and protective substances within the bronchalveolar compartment, we asked the following questions: 1) Is there a correlation between concentration and function of alpha $a_{1}$-PI in bronchoalveolar lavage fluid (BALF)? 2) Is inactivation of alpha ${ }_{1}$-PI due to oxidation, complexation or irreversible proteolysis? 3) Is it possible to obtain an index of the imbalance of the proteinase-antiproteinase system in patients suffering from acute pneumonia, which may be useful for therapeutic intervention?

\section{Materials and methods}

\section{Study population}

Twenty one immunocompetent patients (Group I) (table 1) with either severe community-acquired pneumonia $(n=7)$, or severe nosocomial pneumonia $(n=14)$, were studied. Indication for BAL was failure of empirical antibiotic treatment within 3-5 days after onset of symptoms $(n=17)$, or admission to the intensive care unit $(n=4)$. The mean period between onset of symptoms and BAL was $95.3 \pm 51.3 \mathrm{~h}$. Antibiotic treatment was discontinued at least $24 \mathrm{~h}$ before examination. The underlying illnesses 
Table 1. - Demographic data: groups I-IV

\begin{tabular}{lcccc}
\hline & Group I & Group II & Group III & Group IV \\
\hline Subjects n & 21 & 19 & 9 & 10 \\
Age yrs mean & 58 & 38 & 59 & 24 \\
$\quad$ range & $21-76$ & $29-49$ & $48-71$ & $21-27$ \\
Sex M/F & $13 / 8$ & $13 / 6$ & $6 / 3$ & $10 / 0$ \\
Smokers n & 13 & 8 & 7 & 4 \\
Nonsmokers n & 8 & 11 & 2 & 6 \\
Pathogen & & & & 0 \\
$>10$ CFU·ml-1 & 16 & 14 & 0 & 10 \\
<10 CFU·ml-1 & 5 & 5 & 9 & 0 \\
Survived n & 19 & 17 & 9 & \\
Death n & 2 & 2 & 0 & - \\
Radiology & & 2 & - & - \\
Alveolar pneumonia & 3 & 13 & - & - \\
Bronchopneumonia & 14 & 6 & - & \\
Interstitial & 4 & & & \\
\hline
\end{tabular}

Group I: patients with acute pneumonia (n=21); Group II: immunocompromised patients with acute pneumonia ( $\mathrm{n}=19)$; Group III: patients successfully treated for pneumonia $(\mathrm{n}=9)$; group IV: healthy volunteers $(n=10)$. CFU: colony forming units.

were: chronic obstructive lung disease ( $n=8$; two patients with bronchiectasia); coronary heart disease with chronic congestion $(n=4)$, chronic alcoholism $(n=2)$, diabetes mellitus $(n=1)$ and severe deformity of the thorax $(n=1)$. In five cases no predisposing conditions were detectable. The patients were diagnosed as having pneumonia when the following criteria were fulfilled: a typical clinical appearance with fever, purulent phlegm and dyspnoea; a new infiltrate on the chest X-rays; as well as evidence obtained from laboratory test (i.e. elevated erythrocyte sedimentation rate, elevated C-reactive protein, leucocytosis with elevation of immature cell forms). In addition, the response to antibiotic treatment was taken into account.

Nineteen immunocompromised patients were studied (Group II: post renal transplant $(n=10)$ receiving threefold immunosuppression with cyclosporin A, azathioprine and methylprednisolone; human immunodeficiency virus (HIV)-infection Center for Disease Control (CDC) stage IV $(n=9)$ (table 1). The mean period between onset of symptoms and BAL was $35.3 \pm 21.3 \mathrm{~h}$.

For comparison, 9 patients successfully treated for pneumonia (Group III) (table 1) were studied. In these patients, bronchoscopy was performed to exclude a bronchial carcinoma as the cause of pneumonia. The mean period between onset of symptoms and bronchoalveolar lavage was $246 \pm 72 \mathrm{~h}$. Group IV consisted of healthy volunteers (table 1). This study received approval from the local Ethics Committee

\section{Bronchoalveolar lavage}

Bronchoalveolar lavage [12] was carried out under local anaesthesia with $2 \%$ lidocain, after pre-medication with 2.5-7.5 mg midazolam, using a fibreoptic bronchoscope. On average, $200 \mathrm{ml} 0.15 \mathrm{~mol} \cdot l^{-1}$ was instilled in $20 \mathrm{ml}$ aliquots. Each aliquot was aspirated immediately following instillation, the first fraction being discarded, the following portions being pooled before further processing. BAL was performed at the beginning of bronchoscopy and prior to endo- or transbronchial biopsies to avoid contamination with blood. Red blood cell (RBC) contamination was assessed using microscopy. The mean recovery of instilled fluid was: Group I 57\%, Group II $65 \%$, Group III $69 \%$ and Group IV $71 \%$.

In patients with localized infiltrations, the lavage was carried out in this area. In those patients with diffuse infiltrates or in controls, the lavage was carried out in the lateral segment of the right middle lobe. The BAL was centrifuged at $200 \times \mathrm{g}$ for $10 \mathrm{~min}$ and the cell-free supernatant (BALF) and cell-pellet were then separated. After cell count, the pellet was stained according to WrightGiemsa, and the percentage of the different cell types determined by counting at least 600 cells.

\section{Microbiology}

Quantitative bacterial culture was carried out, as described previously [13]. The identification of the microorganisms was performed according to the recommendations of the German Society of Hygiene and Microbiology and the Manual of Clinical Microbiology [14].

\section{Protein concentration measurements}

Alpha $_{1}$-PI, elastase (measured in complex with alpha ${ }_{1}^{-}$ PI), MPO and albumin were determined by immunoluminometric assays $[15,16]$. Both the absolute concentrations and those standardized with respect to albumin were used.

\section{Elastase inhibition capacity (EIC)}

After centrifugation of the BAL, the supernatant (BALF) was concentrated 40 fold by using a microconcentrator (Centricon 10, Amicon, Witten, Germany). Two millilitres of BALF were concentrated by centrifugation at 
$5,000 \times \mathrm{g}$ for $90 \mathrm{~min}$ at a rotor angle of $45^{\circ}$. EIC was measured using the activity of elastase upon the synthetic substrate Meo-Suc-Ala-Ala-Pro-Val-p-nitroanilide (Protogen, Laufingen, $\mathrm{CH})$ [17-19].

Ten microlitre sample or medium (blank), $100 \mu \mathrm{l}$ assaybuffer ( $1 \mathrm{~mol} \cdot l^{-1}$ hydroxyethylpiperazine ethanesulphonic acid (HEPES), $0.5 \mathrm{~mol} \cdot l^{-1} \mathrm{NaCl}, \mathrm{pH} 7.5$ ) and $10 \mu \mathrm{l}$ human leucocyte elastase $\left(1 \mathrm{kU} \cdot l^{-1}\right.$ in $0.1 \mathrm{~mol} \cdot l^{-1}$ Tris buffer, $\mathrm{pH} 7.5$ ) were incubated for $5 \mathrm{~min}$ at $25^{\circ} \mathrm{C}$. After addition of $100 \mu \mathrm{l}$ substrate $(0.17 \mu \mathrm{mol})$, the extinction was measured kinetically at $405 \mathrm{~nm}$. The EIC was calculated from the formula: $\mathrm{F} \times\left[\mathrm{dE}\right.$ blank $\cdot \mathrm{min}^{-1}-\mathrm{dE}$ sample $\left.\cdot \mathrm{min}^{-1}\right]=\mathrm{U} \cdot l^{-1}$ where $\mathrm{dE}$ is the difference in extinction, $\mathrm{F}=2.15 \times \mathrm{K}$, where $\mathrm{K}=$ molar extinction coefficient $\mathrm{E}$ $\left(\mathrm{E}=10,200 l \times \mathrm{mol}^{-1} \times \mathrm{cm}^{-1}\right)$. In cases of free elastase activity, the difference in extinction of the sample ( $\mathrm{dE}$ sample $\cdot \mathrm{min}^{-1}$ ) was higher than the difference of the blank $\left(\mathrm{dE}\right.$ blank $\left.\cdot \mathrm{min}^{-1}\right)$. This was further confirmed by photometrical end-point measurement. In this case, different dilutions of elastase were used, and the extinction was measured $24 \mathrm{~h}$ after addition of the substrate. $1 \mathrm{IU}$ of elastase activity proteolyses $1 \mathrm{mg}$ of elastin in $20 \mathrm{~min}-$ utes, 1 IU of EIC inhibits this activity.

\section{Functional activity of alpha $a_{1}-P I$}

As $90 \%$ of the EIC in the lower respiratory tract is accounted for by alpha ${ }_{1}$-PI [4], the ratio between the EIC and the alpha $a_{1}$-PI concentration represents approximately the functional activity of alpha 1 -PI. This was expressed as the percentage of the calculated full activity of the inhibitor (i.e. $14.4 \mathrm{U} \cdot \mathrm{g}^{-1}$ alpha $_{1}$-PI), using an elastase preparation of $25 \mathrm{kU} \cdot \mathrm{g}^{-1}$ and a molar inhibition ratio of $1: 1[4]$.

\section{Oxidized alpha $_{1}-P I$}

To monitor the slower inhibition of oxidized alpha 1 -PI [20], the EIC was determined not only after 5 min incubation but also after $60 \mathrm{~min}$ in BALF of 10 patients with acute pneumonia (Group I) and of the healthy controls (Group IV). Here the functional activity (after $5 \mathrm{~min}$ ) was subtracted from the $60 \mathrm{~min}$ value, which gave an estimate of the oxidized alpha 1 -PI. For further confir- mation of these findings, 10 BALF samples obtained both from Group I and Group IV were subjected to in vitro oxidation prior to ultracentrifugation. This was done to distinguish between alpha ${ }_{1}$-PI, that was already oxidized in vivo (no change expected) and not yet oxidized alpha $_{1}$-PI. For this, a cell free system was used, consisting of $0.1 \mathrm{mg}$ hydroxylamine, $0.07 \mathrm{mg}$ hypoxanthine and $30 \mu \mathrm{l}$ xanthine oxidase, which were added to a $2 \mathrm{ml}$ BALF sample, and incubated for $60 \mathrm{~min}$ at $25^{\circ} \mathrm{C}$ with shaking. The reaction was designed to produce $\mathrm{O}_{2}$ ions analogous to those produced during phagocytosis. After separation of the reaction mixture via ultracentrifugation, the EIC of the resulting supernatant was measured. The percentage difference of the EIC as well as the functional activity of alpha ${ }_{1}$-PI were measured in BALF, before oxidation $(=100 \%)$ and after the oxidation procedure.

Different methods of quantification and calculation of alpha $a_{1}$-proteinase inhibitor concentration and function are shown in table 2 .

\section{Statistics}

Non-parametric statistics were used throughout the study. The Wilcoxon signed rank test was used for paired samples, the Kruskal-Wallis-test for independent samples. Correlations were made with the Spearman rank correlation. The median was used as a marker of central tendency.

\section{Results}

The following micro-organisms were found in significant numbers $\left(\right.$ i.e. $>10^{4}$ colony forming units $\left.(\mathrm{CFU}) \cdot \mathrm{ml}^{-1}\right)$ in the BAL of the immunocompetent patients (Group I): Haemophilus influenzae $(\mathrm{n}=5)$, Klebsiella pneumoniae $(\mathrm{n}=3)$, Staphylococcus aureus $(\mathrm{n}=3)$, Bacteroides sp. $(\mathrm{n}=2)$, Legionella pneumophila $(\mathrm{n}=1)$, Candida albicans $(\mathrm{n}=1)$ and Aspergillus fumigatus $(\mathrm{n}=1)$. Five samples remained nondiagnostic. In immunocompromised patients (Group II) the following micro-organisms were found: Pneumocystis carinii $(\mathrm{n}=6)$ cytomegalovirus $(\mathrm{n}=4)$, Aspergillus fumigatus $(\mathrm{n}=2)$, Branhamella catarrhalis $(\mathrm{n}=1)$ and Staphylococcus aureus $(\mathrm{n}=1)$. Five samples remained nondiagnostic. In groups III and IV there were no pathogens in significant number detectable $\left(<10^{4} \mathrm{CFU} \cdot \mathrm{ml}^{-1}\right)$.

Table 2. - Quantification and calculation of $\alpha_{1}$-proteinase inhibitor concentration and function

\begin{tabular}{ll}
\hline Parameter & Method \\
Elastase inhibition capacity (EIC) & Photometrical determination IU.ml-1 \\
Elastase activity & Photometrical determination $\mathrm{U} \cdot \mathrm{ml}^{-1}$ \\
Total $\alpha_{1}$-PI & Immunoluminometric assay $\mathrm{mg} \cdot l^{-1}$ \\
$\alpha_{1}$-PI-elastase-complex (Ela) & Immunoluminometric assay $\mathrm{mg} \cdot l^{-1}$ \\
& Calculation \\
Completely active $\alpha_{1}$-PI & $25 \mathrm{U} \cdot \mathrm{mg}-1 \mathrm{Ela}=14.4 \mathrm{IU} \cdot \mathrm{mg}^{-1} \alpha_{1}$-PI $=100 \%$ functional activity \\
Functional $\alpha_{1}$-PI-activity (EIQ) & $(\mathrm{EIC}) / \alpha_{1}$-PI) in $\%$ of completely active $\alpha_{1}$-PI \\
Oxidized $\alpha_{1}$-PI & EIQ after $60 \mathrm{~min} *$-EIQ after 5 min incubation with elastase [\%] \\
Inactive $\alpha_{1}$-PI & $100 \%-\left(\right.$ EIQ + oxidized $\alpha_{1}$-PI + complex $)$ \\
\hline
\end{tabular}

$\alpha_{1}$-PI: alpha ${ }_{1}$-proteinase inhibitor; $*$ : slower inhibition of elastase by oxidized $\alpha_{1}$-PI. 
Table 3. - Neutrophil count, protein concentrations, EIC and functional activity of alpha $_{1}-\mathrm{PI}$ in BAL of subjects studied

a) Absolute concentrations

\begin{tabular}{|c|c|c|c|c|c|}
\hline & $\begin{array}{c}\text { Neutrophils } \\
\%\end{array}$ & $\begin{array}{l}\text { alpha }_{1} \text {-PI } \\
\mathrm{mg} \cdot l^{-1}\end{array}$ & $\begin{array}{c}\mathrm{EIC} \\
\mathrm{mIU} \cdot \mathrm{ml}^{-1}\end{array}$ & $\begin{array}{l}\text { Funct.alpha } \\
\%\end{array}$ & $\begin{array}{l}\mathrm{Alb} \\
\mathrm{mg} \cdot l^{-1}\end{array}$ \\
\hline \multicolumn{6}{|l|}{ Group I } \\
\hline Median & 51 & 2.8 & 0.86 & 2.2 & 15.7 \\
\hline Mean & 50.9 & 13 & 0.69 & 4.4 & 50.59 \\
\hline$(16-84 \%)$ & $(10-87)$ & $(1.22-10.5)$ & $(-5.38-3.87)$ & $(0-10.8)$ & $(3.5-5.2)$ \\
\hline \multicolumn{6}{|l|}{ Group II } \\
\hline Median & 7 & 3.2 & 6.13 & 13.9 & 23.2 \\
\hline Mean & 18.6 & 4.22 & 8.36 & 15.3 & 28.65 \\
\hline$(16-84 \%)$ & $(1-46)$ & $(1.38-5.4)$ & $(0.75-14.4)$ & $(3.1-22.6)$ & $(11-45)$ \\
\hline \multicolumn{6}{|l|}{ Group III } \\
\hline Median & 3 & 0.91 & 2.15 & 26.4 & 11 \\
\hline mean & 7.8 & 2.65 & 5.84 & 27.6 & 18.87 \\
\hline$(16-84 \%)$ & $(0-5)$ & $(0.23-3.66)$ & $(0-9.68)$ & $(0-45.7)$ & $(6.3-18.9)$ \\
\hline \multicolumn{6}{|l|}{ Group IV } \\
\hline Median & 0 & 0.25 & 1.77 & 59 & 16 \\
\hline Mean & 0.2 & 0.33 & 1.73 & 52.8 & 16.24 \\
\hline$(16-84 \%)$ & $(0-0)$ & $(0.11-0.31)$ & $(1.8-2.15)$ & $(27.8-68.2)$ & $(7.3-35)$ \\
\hline
\end{tabular}

b) Concentrations standardized with respect to albumin

\begin{tabular}{|c|c|c|c|c|}
\hline & $\begin{array}{c}\text { alpha }-\mathrm{PI} / \mathrm{Alb} \\
\mu \mathrm{g} \cdot \mathrm{mg}^{-1}\end{array}$ & $\begin{array}{l}\mathrm{EIC} / \mathrm{Alb} \\
\mathrm{mIU} \cdot \mathrm{mg}^{-1}\end{array}$ & $\begin{array}{c}\text { Elastase/Alb } \\
\mu \mathrm{g} \cdot \mathrm{mg}^{-1}\end{array}$ & $\begin{array}{l}\mathrm{MPO} / \mathrm{Alb} \\
\mu \mathrm{g} \cdot \mathrm{mg}^{-1}\end{array}$ \\
\hline $\begin{array}{l}\text { Group I } \\
\text { Median } \\
\text { Mean } \\
(16-84 \%)\end{array}$ & $\begin{array}{c}201.9 \\
556.6 \\
(77.7-611)\end{array}$ & $\begin{array}{c}27.9 \\
21.8 \\
(-94-338)\end{array}$ & $\begin{array}{c}8 \\
12.5 \\
(1.1-21.9)\end{array}$ & $\begin{array}{c}57.7 \\
136.6 \\
(4.3-174)\end{array}$ \\
\hline $\begin{array}{l}\text { Group II } \\
\text { Median } \\
\text { Mean } \\
(16-84 \%)\end{array}$ & $\begin{array}{c}148 \\
174.5 \\
(71-233)\end{array}$ & $\begin{array}{c}297 \\
373.7 \\
(32-561)\end{array}$ & $\begin{array}{c}1.05 \\
1.94 \\
(0.33-2.0)\end{array}$ & $\begin{array}{c}5.1 \\
14.1 \\
(1.2-13.1)\end{array}$ \\
\hline $\begin{array}{l}\text { Group III } \\
\text { Median } \\
\text { Mean } \\
(16-84 \%)\end{array}$ & $\begin{array}{c}104.2 \\
99 \\
(16.4-151.5)\end{array}$ & $\begin{array}{l}197.2 \\
383.4 \\
(0.1-841)\end{array}$ & $\begin{array}{c}0.6 \\
1 \\
(0.3-1.4)\end{array}$ & $\begin{array}{c}1.8 \\
4.8 \\
(0.4-8.2)\end{array}$ \\
\hline $\begin{array}{l}\text { Group IV } \\
\text { Median } \\
\text { Mean } \\
(16-84 \%)\end{array}$ & $\begin{array}{c}15.4 \\
21.2 \\
(9.1-35.6)\end{array}$ & $\begin{array}{c}102.6 \\
132.6 \\
(76.9-198.6)\end{array}$ & $\begin{array}{c}0.1 \\
3.24 \\
(0.1-0.33)\end{array}$ & $\begin{array}{l}0.01 \\
0.24 \\
(0-0.01)\end{array}$ \\
\hline
\end{tabular}

EIC: elastase inhibition capacity; alpha ${ }_{1}$-PI: alpha $a_{1}$-proteinase inhibitor; Alb: albumin; MPO: myeloperoxidase; 16-84\%: 16th to 84th percentile. Funct.: functional For explanation of groups see legend to table 1 .

Table 3a shows the BALF concentration of alpha $a_{1}$-PI. The alpha $a_{1}$-PI concentrations in Group I and II were higher than in group III $(\mathrm{p}<0.03)$ and Group IV $(\mathrm{p}<0.01)$. The functional activity of alpha 1 -PI in Group I was significantly lower than in group II-IV ( $\mathrm{p}<0.01$ in all cases) (table $3 \mathrm{a})$. The functional activity of alpha 1 -PI lay below the 16 th percentile of the healthy controls (Group IV) in 20 of the 21 patients with pneumonia (Group I). In comparison, only 9 of the 19 immunocompromised patients with pneumonia (Group II) and 3 of the 9 with treated pneumonia (Group III) lay under the 16th percentile. Both the concentration of MPO and of elastase-alpha ${ }_{1}$-PI complex were about 100 times higher in immunocompetent patients with pneumonia than in healthy controls $(\mathrm{p}<0.001)$ (fig. 1$)$.

The EIC in the BALF in patients with acute pneumonia varied greatly, as can be seen in figure 2, which also shows that in 6 of the 21 patients in Group I, and one from Group II, free elastase activity was demonstrable, despite the fact that alpha 1 -PI was elevated in these cases. Table $3 \mathrm{a}$ summarizes the absolute concentrations, and table $3 \mathrm{~b}$ concentrations standardized with respect to albumin, of alpha 1 -PI and albumin, as well as the EIC and 


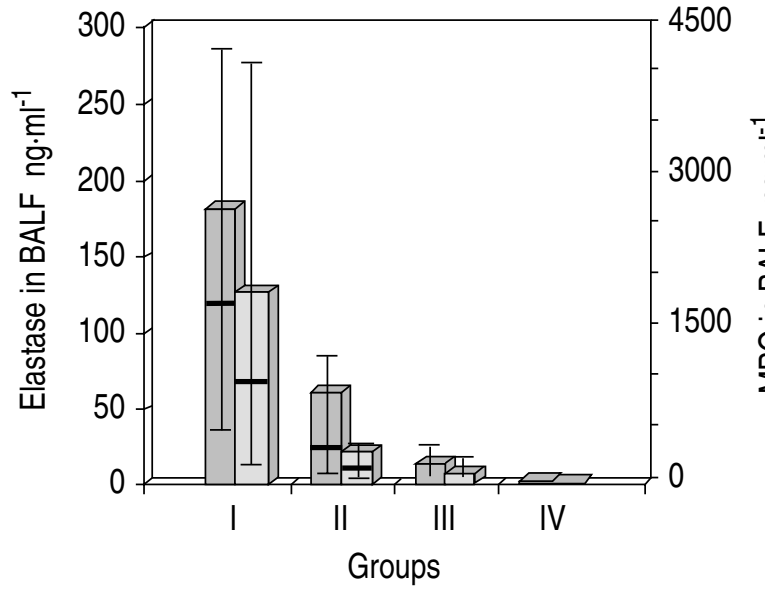

Fig. 1. - Mean of elastase and MPO concentration in BAL in Groups I-IV. Data are presented as median (horizontal bars), and 16-84th percentile (vertical bars). MPO: myeloperoxidase; BAL: bronchoalveolar lavage; BALF: BAL fluid. Group I: patients with acute pneumonia $(\mathrm{n}=21)$; Group II: immunocompromised patients with acute pneumonia $(n=-19)$; Group III: patients successfully treated for pneumonia $(n=9)$; group IV: healthy volunteers $(n=10)$. $\square$ : elastase; $\square$ : MPO.

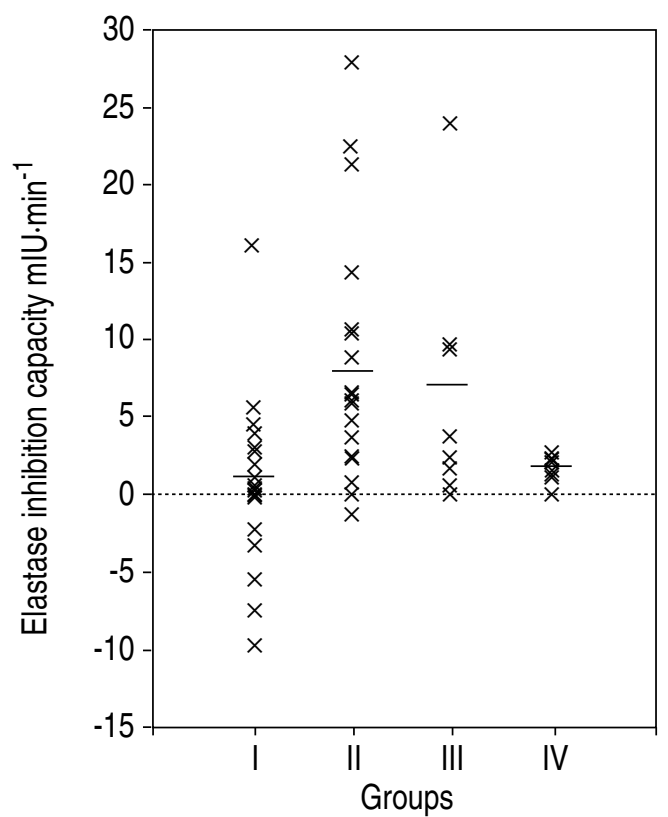

Fig. 2. - Elastase inhibition capacity in BAL in groups I-IV. Bars indicate mean value. For abbreviations and explanation of groups see legend to figure 1 .

functional activity of alpha $a_{1}$-PI. There were no statistically significant differences between patients with or without documented bacteria in BAL, with regard to protein concentration or function (data not shown).

A granulocytosis was seen in the differential cell count of most pneumonia patients, especially in Group I (51\%), whereas Groups II-IV had a lower percentage of granulocytes (Group II 18.6\%, Group III 7.8\% and Group IV $0.2 \%, p<0.01$ in all cases). The percentage of granulocytes in patients with acute pneumonia (Group I) correlated with the functional activity of alpha 1 -PI $(\mathrm{r}=-0.53$, $\mathrm{p}<0.03$ ). The BALF concentrations of elastase and MPO showed a similar negative correlation with the functional a) Healthy vounteer - Group IV

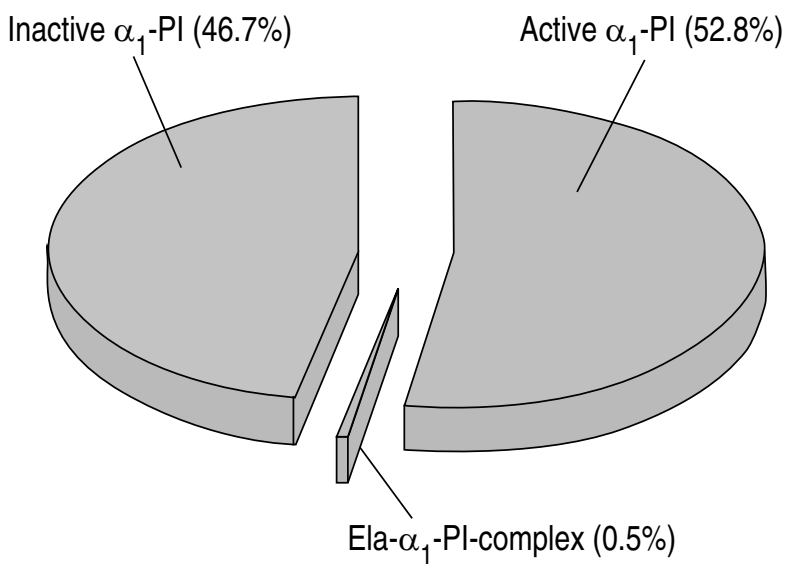

b) Patients with pneumonia - Group 1

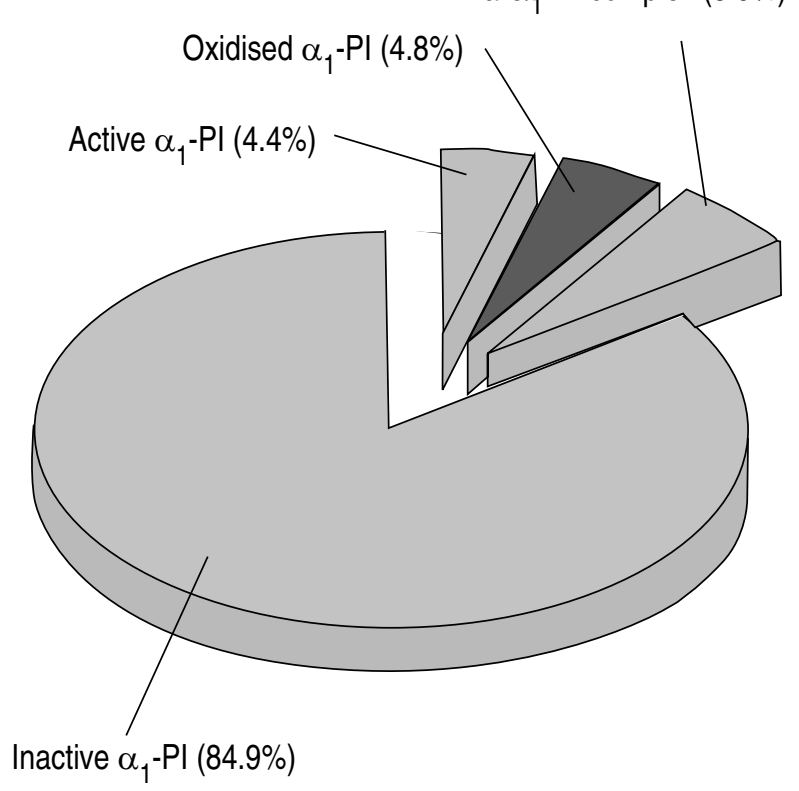

Fig. 3. - Proportion of active, inactive, oxidized and complexed proteinase inhibitor (for explanation see also table 2). a) Healthy volunteers (Group IV); and b) patients with pneumonia (Group I). Oxidized alpha ${ }_{1}$-PI was determined in 10 of the 21 Group I patients. $\alpha_{1}$-PI: alpha ${ }_{1}$-proteinase inhibitor; Ela: elastase.

activity of alpha ${ }_{1}$-PI: elastase $\mathrm{r}=-0.50$; MPO r=-0.47; $\mathrm{p}<0.04)$. Whereas, in Groups II-IV no correlation could be demonstrated between MPO and alpha ${ }_{1}$-PI (Group II $\mathrm{r}=-0.37$, Group III $\mathrm{r}=-0.1$, Group IV $\mathrm{r}=0.1$ ).

The proportion of oxidized alpha $a_{1}$-PI was highest in Group I (4.8\%); whereas, in healthy controls (Group IV) no oxidized inhibitor could be detected. After in vitro oxidation, the EIC in Group I was reduced by about $13 \%$, showing that most of the active alpha 1 -PI was already oxidized in vivo. In contrast to this, in Group IV EIC could be reduced by $49 \%$ by in vitro oxidation. These results are summarized in figure 3 , showing the proportion of native, complexed, oxidized and inactive alpha ${ }_{1}$-PI. 


\section{Discussion}

The main finding of this study was, that patients with acute pneumonia had a marked reduction in their functional activity of alpha $a_{1}$-PI. Despite elevated alpha ${ }_{1}$-PI concentration, functional activity of alpha ${ }_{1}$-PI was low when compared with the healthy volunteers. In six patients in Group I, free elastase activity was seen in the BALF. This imbalance of reduced function and high concentration of alpha ${ }_{1}$-PI probably results from the action of neutrophil products, as is demonstrated by a negative correlation between the concentration of elastase and MPO on one hand, and the active alpha $a_{1}$-PI on the other, in patients with acute pneumonia.

Similar findings have been documented by ABRAMs et al. [21], who measured a reduced EIC using albumin as marker, in the BALF of 13 pneumonia patients, despite elevated alpha ${ }_{1}$-PI concentrations. This elevation of alpha ${ }_{1}^{-}$ PI in patients with pneumonia probably reflects an increased permeability of the endothelial-interstitial-epithelial barrier, seen as a result of the inflammatory process in which plasma proteins diffuse into the alveolar space. This increase is nonspecific, and can also be seen in patients with bronchial carcinoma and sarcoidosis [22].

Activated neutrophils release both elastase and MPO, as well as reactive oxygen species, into the extracellular space. In case of an excess of active alpha ${ }_{1}$-PI this complexes with elastase and inactivates the latter [3]. On the other hand, an excess of elastase leads to proteolysis and irreversible damage of alpha $a_{1}$-PI, before complexation is accomplished. The catalytic activity of MPO with hydrogen peroxide and $\mathrm{Cl}^{-}$gives rise to highly reactive oxygen species, including $\mathrm{O}_{2}{ }^{-}$and $\mathrm{HOCl}$ which can oxidize the alpha 1 -PI, especially the methionine in the active centre of the molecule. After oxidation, alpha $a_{1}$-PI has a much lower affinity (about 2,000×) to elastase [10, 23]. CARP and JANOFF [11] have demonstrated the suppression of EIC with reactive oxygen species from granulocytes in vitro. Matheson et al. [23] showed that MPO in the presence of $\mathrm{H}_{2} \mathrm{O}_{2}$ and $\mathrm{Cl}^{-}$suppresses the functional activity of alpha $a_{1}$-PI, and that this is dependent upon the concentration of $\mathrm{MPO}, \mathrm{H}_{2} \mathrm{O}_{2}$ and $\mathrm{Cl}^{-}$. In bronchial perfusion experiments, it has been shown that plasma-inhibitors were destroyed in animals with induced pneumonia [24]. The pulmonary venous EIC was lower than the pulmonary arterial EIC in these animals. Similar results were also found by VAN EEDEN and BEER [25] in acute pneumonia patients.

We oxidized BALF in vitro to calculate the proportion of oxidized alpha 1 -PI. The BALF of the healthy volunteers (Group IV) showed a higher loss in EIC than that from the pneumonia patients (Group I), showing that the latter had a higher percentage of oxidized alpha ${ }_{1}$-PI. This was probably due to the in vitro processes invoked by oxidants which are released into the alveolar space.

In immunocompromised patients, we found a significantly lower percentage of neutrophils than in group I, despite the fact that the severity of pneumonia was comparable in both groups. Similarly, the concentrations of the neutrophil products were lower when compared to immunocompetent patients, This may be due to the shorter duration between onset of symptoms and lavage procedure. However, the fact that the functional activity of alpha $_{1}$-PI was higher in the BALF of immunocompromised patients, supports the hypothesis that the hampered function of alpha 1 -PI was due to neutrophil products.

To conclude, this study demonstrates a massive, and mostly irreversible, reduction in the functional activity of alpha 1 -PI in patients with acute pneumonia. It is most probably due to neutrophil products; the reactive oxygen species produced by neutrophils are able to oxidise alpha a $^{-}$ PI [26], making it more susceptible to proteolysis by elastase [20]. In addition, oxidized alpha ${ }_{1}$-PI needs longer to inactivate elastase. Thus, the measurement of the functional activity of alpha $a_{1}$-PI in BALF allows an assessment of the balance between aggressive factors (elastase, MPO, oxygen radicals) as well as the protective factors (especially alpha ${ }_{1}$-PI). It is a marker in addition to the concentrations of the BALF proteins themselves (elastase-alpha ${ }_{1}$-PI complex, MPO, alpha ${ }_{1}$-PI, albumin) [27]. The detection of low activity of alpha $a_{1}$-PI in BALF helps to identify patients with a protease-antiprotease imbalance. Further studies of larger patient groups are necessary to evaluate whether the reduction of functionally active alpha 1 -PI is related to a complicated course and poor outcome, and whether these patients profit from already available therapeutic options, such as antioxidant treatment (e.g. N-acetylcysteine) [28], or infusion of active alpha ${ }_{1}^{-}$ PI.

\section{References}

1. Center for Disease Control annual summary. Morb Mort Weekly Rep 1980; 28: 54-55.

2. Lehrer RI, Ganz T, Selsted ME, Babior BM, Curnutte JT. - Neutrophils in host defense. Ann Intern Med 1988; 109: 127-142.

3. Babior BM. - Oxygen-dependent microbial killing by phagocytes. N Engl J Med 1978; 298: 659-668.

4. Janoff A. - Elastase and emphysema. Current assessment of the protease-antiprotease hypothesis. Am Rev Respir Dis 1985; 132: 417-433.

5. Gadek JE, Fells GA, Zimmermann RL, Rennard SI. Antielastases of the human alveolar structures: implications for the protease-antiprotease theory of emphysema. J Clin Invest 1981; 68: 889-893.

6. Janoff A, Sandhaus RA, Hospelhorn VD, Rosenberg R. - Digestion of lung proteins by human leukocyte granules in vitro. Proc Soc Exp Biol Med 1972; 140: 516-519.

7. Janoff A, Sloan B, Weinbaum G, et al. - Experimental emphysema induced with purified human neutrophil elastase: tissue localization of the instilled protease. Am Rev Respir Dis 1977; 115: 461-478.

8. Snider GL, Lucey EC, Christensen TG. - Emphysema and bronchial secretory cell metaplasia induced in hamsters by human neutrophil products. Am Rev Respir Dis 1984; 129: 155-160.

9. Modig J, Hallgren R. - Pathophysiologic significance of lung granulocytes in human adult respiratory distress syndrome induced by septic or traumatic shock. Acta Chir Scand 1987; 153: 267-271.

10. Beatty K, Bieth J, Travis J. - Kinetics of association of serin proteinases with native and oxidized $\alpha_{1}$ proteinase in- hibitor and $\alpha_{1}$-antichymotrypsin. J Biol Chem 1980; 255: 3931- 3934. 
11. Carp H. Janoff A. - In vitro suppression of serum elastase-inhibitory capacity by reactive oxygen species generated by phagocytosing polymorphonuclear leukocytes. J Clin Invest 1979; 63: 793-797.

12. Reynolds HY, Newball HH. - Analysis of proteins and respiratory cells obtained from human lungs by bronchial lavage. J Lab Clin Med 1974; 84: 559-573.

13. Dahlhoff K, Baun J, Wießmann KJ, Hollandt H, Marre R. - Bronchoskopische Pneumoniediagnostik mit quantiativer Keimzahlbestimmung. Deutsch Med Wochenschr 1990; 115: 1459-1465.

14. Lennette EH, Ballows A, Haulser WJ, Skadomy HJ. Manual of clinical microbiology. Washington, American society of Microbiology, 1985.

15. Braun J, Schultek T, Tegtmeier K-F, Florenz A, Rohde C, Wood WG. - Luminometric assays of seven acutephase proteins in minimal volumes of serum, plasma, sputum and bronchoalveolar lavage. Clin Chem 1986; 32: 743-747.

16. Janda J, Jaensch H, Braun J, Wood WG. - A comparison of four immunometric assays for myeloperoxidase using luminescent and colorimetric signal detection. $J$ Clin Chem Clin Biochem 1990; 28: 475-480.

17. Geiger R, Junk A, Jochum M. - Isolation and characterisation of porcine leukocyte elastase. J Clin Chem Clin Biochem 1985; 23: 821-828.

18. Nakajima K, Powers JC, Ashe BM, Zimmerman M. Mapping the extended substrata binding site of cathepsin G and human leukocyte elastase. J Biol Chem 1979; 254: 4027-4032.

19. Braun J, Schaaf B, Dalhoff K, Wood WG. - Measure- ment of elastase inhibition capacity in bronchoalveolar lavage fluid: increase of sensitivity by ultracentrifugation. Lab Med 1992; 16: 123-127.

20. Padrines M, Schneider-Pozzer M, Bieth J. - Inhibition of neutrophil elastase by alpha ${ }_{1}$-proteinase inhibitor oxidized by activated neutrophils. Am Rev Respir Dis 1989; 139: 783-790.

21. Abrams WR, Fein AM, Kacich U. - Proteinase inhibitory function in inflammatory lung disease: acute bacterial pneumonia. Am Rev Respir Dis 1984; 129: 735.

22. Schultek T, Braun J, Wiessmann KJ, Wood WG. Bronchoalveolar lavage. The humoral parameter spectrum in bronchial carcinoma and chronic bronchitis. Dtsch Med Wochenschr 1986; 9: 333-337.

23. Matheson NR, Wong PS, Schyler M, Travis J. Interaction of human $\alpha_{1}$-proteinase inhibitor with neutrophil myeloperoxidase. Biochemistry 1981; 20: 331-336.

24. Maran AG, Küppers F. - Pulmonary arteriovenous differences in serum antiprotease activity during experimental pneumonitis. Am Rev Respir Dis 1975; 112: 527-534.

25. van Eeden SF, Beer Pde. - Community-aquired pneumonia: evidence of functional inactivation during experimental pneumonitis. Crit Care Med 1990; 18: 1204-1209.

26. Sibille Y, Martinot JB, Polomski LL, et al. - Phagocyte enzymes in bronchoalveolar lavage from patients with pulmonary sarcoidosis and collagen vascular disorders. Eur Respir J 1990; 3: 249-256.

27. Weiss SJ. - Tissue destruction by neutrophils. $N$ Engl J Med 1989; 320: 365-376.

28. Maier KL. - How the lung deals with oxidants. Eur Respir J 1993; 6: 334-336. 